\title{
An exploratory study of information availability and exploitation by the rural women of Melmoth, KwaZulu-Natal
}

\author{
Veli Jiyane \\ University of Zululand Library, P/B x I00I KwaDlangezwa 3886 \\ gvjiyane@pan.uzulu.ac.za
}

and

\section{Dennis N.Ocholla}

Department of Library and Information Science, University of Zululand, P/B x I00I KwaDlangezwa 388 docholla@pan.uzulu.ac.za

Received: 27th February 2003

Revised: 30 $0^{\text {th }}$ October 2003

\begin{abstract}
The article reports on a study that explored the information needs of the rural women and how they are fulfilled in the area of Melmoth, KwaZulu-Natal. Through a normative survey method and critical incident technique, 109 women were interviewed and questionnaires administered to 18 community leaders. Observation was also used to collect primary data.The study found that there is a need for suitable information on agriculture, health, education, business, legal and career opportunities as well as self-help related activities. Such information should be available closer to the home environment, in visual and sound formats, orally delivered by people closer to the community such as friends, relatives and neighbours as well as community leaders. Methods of information transmission should be overwhelmingly oral, including greater use of radio and television transmission. Largely, the findings are consistent with similar studies conducted elsewhere in the developing countries.
\end{abstract}

\section{Introduction}

Women comprise $52 \%$ of the population of the Republic of South Africa. According to the report by Henderson (2003), South Africa's population was estimated by Statistics South Africa to be 45.5 million by mid-2002, without additional deaths caused by AIDS. When additional deaths caused by AIDS were taken into account, the estimate dropped to 45.2 million (Henderson, 2003:I). The author further states that as women are $52 \%$ of the total population, they number 1.7 million more than men. Evidently, females occur in large numbers in South Africa. They are, in practical terms, significant members of each and every household, yet rural people and women in particular bear the largest burden of poverty in South Africa. According to Ngimwa, Ocholla and Ojiambo (1997:46), women are the most exploited and least privileged members of many households in the developing countries. These authors observe that the majority of women are based in rural areas, where their major occupations include farming, childbearing and supporting families in many different ways. Despite all the vital tasks fulfilled by women in households, they are highly marginalised when it comes to the supply and distribution of resources in matters of development.

It is widely known that in many households, especially households of rural blacks in South Africa, men leave homes for urban areas in search of jobs, leaving women behind to maintain the entire household on their own. According to Friedman (1989:4), migration levels for males of working age are considerably higher (51\%) than those for females $(I 5,3 \%)$. The women are therefore left in very remote rural areas where the infrastructure is poorly developed and the distribution of water and electricity is poor. Women are a marginalised community. In high-status fields such as medicine, men are more likely than women to be administrators and surgeons, and occupy powerful positions, whereas women tend to be over represented in the relatively low-status positions (Basow, 1992:264).

The plight of women in the rural parts of South Africa hinders their access to and exploitation of information that can enable them to participate responsibly in all spheres of life. While the significance of South African women in development may have been considered in the past, the present Government is actively promoting gender equality and seeking to improve the lot of rural women and their families (Sotshongaye \& Moller, 2000)

The information needs of women are innumerable. For instance, women need health information. South Africa is faced with the HIV/AIDS epidemic. Recently, KwaZulu-Natal was infected with the cholera epidemic. A woman in the house has to deal with most of these health hazards by nursing or taking care of the family. Information on the 
prevention, healing, nursing, and counselling is essential for them to deal with this mammoth social responsibility. Besides some social and health information needs already mentioned, they require information related to business (e.g. trade, income, investment, saving, banking, profit, insurance, inheritance, property ownership, etc.), agriculture, legal issues, welfare, self-reliance, politics (particularly the knowledge of their rights and responsibilities in the society), food and nutrition, as well as education and many more.

Presumably, through information, women learn to read, write and calculate, think broadly and critically, become selfreliant and liberated and empowered, make decisions concerning their own lives and families, protect the environment and natural resources, support their children's education and secure employment.

The social burden placed on women by society demands a high level of knowledge and information for women to prosper and responsibly know their rights and responsibilities in the society. South Africa as a country comprises many rural settings. One of the poorest and most highly populated provinces in South Africa, following the Eastern Cape, is KwaZulu-Natal, followed by the Northern Province (Polokwane) in terms of poverty (Hirschowits, 2000: 25). A study conducted by Leach reveals that KwaZulu-Natal as a province is very poor, its inhabitants have the least access per capita to development resources, which includes access to information (Leach, 200 I: 163). Leach's observation on the situation in KwaZulu-Natal is dramatically expressed as follows:

The people are under resourced in many ways which affect their ability to access information. Unemployment is well above the national norm; education levels are low and resultantly many people are illiterate. This is particularly true among women. A lack of electrification makes night-reading almost impossible and ideas of using computer based information difficult to implement. Road infrastructure in rural areas has been neglected for decades, making the use of travelling libraries impossible in many communities, and distances are considerable, making access to town libraries very difficult. The fact that most rural dwellers are subsistence farmers with the very long hours of manual work this entails, leaving little time for searching for information in books (Leach, 2001:163).

The Melmoth area in KwaZulu-Natal has a total population of 18604 people, of whom II 199 (60, I \%) are women. Rural districts where infrastructure has not developed characterise Melmoth. In some of the districts there is no electricity, water supply and sanitation, proper roads, communication devices or any other development that can provide people with normal standards of living. Most people are illiterate. They farm cattle and crops for food. Schools and clinics are very limited and in some areas they are $15 \mathrm{~km}$ away. Most women are not formally employed. Very few work in the local hospital, on local farms or as domestic workers for the few white inhabitants and the middle class community.

A public library which caters mostly for the needs of the white commercial farmers and an urban population, who live in the vicinity, is found in town. For the rural women, this library is irrelevant. This irrelevancy is aggravated by illiteracy and poverty. Therefore, it is highly possible that they do not use it and hence access information through other media such as radio and social gatherings, or by mobile clinic staff who visit the area almost once in six months or once a year if possible.

Evidently, without proper access to information women in these rural areas lack opportunities for development and self-reliance. It is observed that, while women tend to bear the heaviest burden in many households in Melmoth, the level of information accessibility and use is relatively low. It is assumed that the social, economic, cultural, and political welfare of women can improve tremendously when relevant information is available and accessible.

The purpose of this study was to investigate the rural women's information availability and exploitation. The objectives were: to explore the information needs of the Melmoth rural women and how they were catered for, to determine how they seek information, to identify and characterise the information available to them, to investigate problems encountered in accessing and using information and to develop a model for information availability and accessibility by the women. It was speculated that rural Melmoth women are not keen to access and use information, that unavailability of relevant information in the appropriate format hinders its exploitation by the Melmoth rural women, and that traditions deter Melmoth women from accessing information.

\section{Methodology}

A descriptive survey, as well as critical incident method (see Fisher and Oulton, 1999) was used in this study. Photographic footage of the rural women performing their daily chores was taken and a record of what was seen and heard from the respondents was made. As the Melmoth rural population is mostly illiterate, it was easy for them to recall incidents when they needed information without contacting recorded sources. The critical incident approach helped the researchers to ask more probing questions for greater insight into the respondents' information needs and seeking. This was applied through the use of face to face interviews. 
Observing the social and economic status of rural women in the Melmoth districts makes it possible to see more similarities in the welfare of the community than differences. Therefore, it was deduced that a smaller or larger sample size taken from this population would make insignificant difference. Ultimately, a purposive sampling technique based on a judgement regarding the characteristics of a representative sample was used. These women typically worked as farm workers and housewives. Other characteristics were illiteracy, poverty and unemployment. From the population of II 199 rural women of Melmoth, a sample size of $1 \%$ was drawn, which produced 109 respondents from six districts. The sample frame was drawn as follows: from Entembeni there were 20 respondents. Nineteen were from Mfanefile and 10 from KwaMagwaza. From Mfule 29 were selected for interview, and from KwaYanguye and Ndundulu 14 and 17 respectively.

The research design was largely qualitative. Specific information gathering instruments included a literature review, questionnaires, interviews and observation. Although the study preferred to use questionnaires with all the respondents because of its widely known advantages, such as giving the respondent freedom to respond independently without interference, in this particular case the tool could not be effectively used because of the low literacy level among the principal respondents (rural women), the majority of whom could not read or write. Ultimately, a few questionnaires were distributed to community workers and opinion leaders, who are largely literate. The closed-ended questions constituted $88 \%$ of all the questions, while $12 \%$ were of the open-ended type. The questions asked included personal information about the rural informants, their information dissemination to the rural women, information gathering and use, and finally, the remarks or comments on information provision.

The interview schedules were largely used for data collection from the women. It is believed by many researchers (e.g. Bailey 1994:84) that the interviews tend to have a better response rate than questionnaires, and that persons who are unable to read and write can still answer questions in an interview. The interview schedule included questions on personal data (name, address, age, marital status and literacy level), questions on occupation and daily working schedule. Other questions included in the interview schedule asked for information about their information needs, information seeking, the availability and accessibility of information, as well as the usage and effectiveness of information. The interviews were conducted largely by using an audio tape recorder that became quite popular with the respondents. Observation always assists the researcher to gain first-hand knowledge of the subjects. Both obtrusive and unobtrusive observation was employed in this study.

After a work plan was drawn up, the questionnaires for the informants as well as the interview schedules to the rural women were prepared. The validity of these instruments was tested on 22 respondents in a pilot study in the Ongoye rural area outside KwaDlangezwa, in KwaZulu-Natal. For the survey proper informants were visited in their homes or places of work. The procedure of completion of questionnaires was explained to them, the questionnaires were distributed and collected after a week. The content analysis method was applied to analyse responses from open-ended questions. The responses were organised and assigned to major categories, then analysed by use of descriptive statistics in order to obtain frequencies and percentages. Other responses from the unstructured questions were grouped together according to their similarities and either summarised or presented as they were.

\section{Results}

The information on personal details of rural women, their information needs and information seeking behavior is presented. Information sources they use when accessing information, and the reasons for being dissatisfied about the information they get, is given. Finally, the obstacles that hinder their access and use of information are outlined.

\section{Personal details}

Items on age, gender, and levels of education were captured. It is noticed that age category 15-20 is not found in large numbers in the Melmoth rural area (16\%). This is totally different from the results from the pilot study which was done in the Ongoye rural area, where the highest number of rural women found represented the age bracket I5-20. The low number of this age bracket in Melmoth could be attributed to the fact that young women who are still active have migrated to cities to search for better jobs and living conditions. The age category $3 \mathrm{I}-40$ is high ( $38 \%)$. Women in this age bracket all over the world are very active and energetic. They bear most of the burden of the households, as was discussed earlier.

Regarding marital status, $71 \%$ of women are married. This is in line with age bracket $31-40$ of rural women found in Melmoth. Expectedly, none of the interviewed women was divorced. This is not surprising, since in rural areas in Africa, divorce is a taboo.

As far as the daily activities are concerned, rural women in the Melmoth area spend most of their time doing household chores. These activities include cooking for the family, fetching water from the rivers, cleaning the house, 
fetching wood from the forests, working in the fields, and more. The activities concur with what is reported in most studies (e.g. Mooko, 2002).

When it comes to education, it was observed that a large number of rural dwellers have poor and low levels of education. It is not unusual that women would be affected most in this social deficiency. For example, $54 \%$ of the rural women have received primary education only, while $35 \%$ have not received any formal education at all. Only $2 \%$ have proceeded to tertiary education. It is no surprise that the Melmoth rural area has $38 \%$ of women who have not gone to school. As was observed, a significant number of rural women found are married while still young. This is possibly one of the reasons, with unemployment and lack of income, why they are not educated. Evidently, in this culture of poverty, it is a tendency of most rural parents to advise a daughter to get married as young as possible in order to bring the 'cows' (wealth) back home. Therefore, they do not only increase the high proportion of illiterate community members, but also that of married women who become household heads while still young, illiterate and inexperienced. It is not surprising that such mothers would discourage rather than encourage their children to go to school and continue with their education.

\section{Information needs}

Mchombu (2000) has noted that one cannot have knowledge unless one gets information. She argues that information equips a person with power, the power to choose and to act in an informed manner. It empowers people towards actions that can transform lives, and allows for a great sense of independence (Mchombu, 2000:42). To Cillie (199I), information is the key to the development of a strong democracy. Our society needs information because it is the key to wealth, to empowering people through knowledge and to create growth and jobs (Cillie,2000:109). The information needs on health, agriculture, transport/road and communication, business, jobs and education exist among these rural women. These needs are in line with what the rural informants have noted. The women explain that they wanted to get information in order to take action in a situation confronting them.

The indication of information need by these women also concurs with what the rural informants observed. They noted that the rural women in Melmoth have come to them for information at one time or another.

\section{Agricultural needs}

Saito et al. (1994) have observed that women work in fields more than men do. According to these authors, not only do women outnumber men in the agricultural labour force, but they also work more hours in agriculture than men. The author gives an example of Kenya, where women spend an average of 6.2 hours per day in agriculture compared to 4.3 for men (Saito et al., 1994:2I). It is quite possible that the women in Melmoth area also, as they work in the sugar-cane and gum-tree plantations owned by white farmers, work under such conditions. Agricultural and farming related information is rated as the highest (35\%) information needed by the women in Melmoth. This opinion could be influenced by the location of the community and high rate of unemployment. They have no purchasing power for their daily needs. Rural women in Melmoth indicate that agricultural related information is needed in order to possess land, practise good farming methods by applying necessary skills and knowledge to reap good yields and products for family consumption and for sale. In addition, they revealed that landlessness, agricultural business, planting and irrigation, farming and obtaining skills are the reasons why they need agricultural information. In a literate community and indeed in westernised society, Purnell and Coetser (200I) observe the necessity and importance of agricultural libraries. Unfortunately, for most of this community, a library is irrelevant, at least for now, unless libraries are radically transformed to cater for the information needs of the rural illiterate, unemployed and poor communities through community oriented collection development and information service policies and strategies.

\section{Business information}

Epstein, in Mchombu (2000), highlights the main factors which motivate rural women to become entrepreneurs; for instance, that there is insufficient land to ensure a livelihood for their families and or lack of employment opportunities. Despite the fact that Melmoth rural women lack sufficient land to cultivate and employment opportunities that would motivate them to venture into business as Epstein reveals, only three percent of the women indicated that they needed business information. We assume that business requires literacy and money and social independence and challenge that may not be accessible to this population.

\section{Security information}

Rutakumwa \& Krogman's (2000) study on rural Ugandan women's views has revealed that, although women in many countries put issues related to personal security and domestic violence at the top of their list, in rural Uganda, violence seems to be considered a normal component of marriage. It is noted that only $2 \%$ of the rural women found in Melmoth have needed information on legal issues and security. With the high level of crime in KwaZulu-Natal, it is ironic that security related information appears irrelevant in Melmoth. This invites argument on whether the women regard living in 
fear of domestic violence, murder, burglary, theft, rape and other crime-related issues that frequently occur in rural areas as normal. Or perhaps insecurity in the rural areas is exaggerated or a norm that people have learnt to live with. Few women $(2 \%)$ who indicated the need for security information expressed fear that their farms can be invaded by other people. Others indicated that they always hear of increasing rape incidents on children and the aged, and therefore fear for themselves and their own children.

\section{Health information}

A study conducted by Sotshongaye \& Moller (2000), in Mavela and Cibane communities in Ndwedwe, revealed that some rural areas in KwaZulu-Natal have access to health resources, while others have little or none. According to this study, the Mavela area has one clinic to serve the entire population. It is located far from the community and poorly equipped. Compared to Entembeni and Mfule communities of Melmoth, where there is no clinic and ambulance service at all, this community is very fortunate. For KwaMagwaza, the community is being helped by the nearby hospital, St. Mary's, the only one in the whole Melmoth area. This health facility is located far from the aged and the sick, whose plight is exacerbated by lack of public transport, especially at night. Ndundulu and Kwayanguye areas have got the clinics but lack adequate health resources.

The eighteen percent of the Melmoth rural women who expressed a need for health information identified their information needs in such areas as nursing/caring for the sick, personal health, sterilisation, contraception and various diseases that were found in the area such as HIVIAIDS and Sexually transmitted diseases (STDs), cholera, asbestosis and tuberculosis. Therefore, it is not strange that rural women in Melmoth would be so concerned about caring for their families, relatives and community members in the midst of these dangerous diseases commonly diagnosed in South Africa. It was expected that health information would be required by more people.

\section{Transport/road information}

Transport information was also indicated as important by rural women (14\%). Unavailability of proper roads and communication infrastructure has been felt by the rural women in the Melmoth area for a long time. The respondents indicated that to buy their groceries, rush the sick to the health centres and to move around is not easy without proper roads. The young rural women who still attend school felt that they arrive at school dirty because they walk on paths with dew and mud after rainfall. The transport problem is experienced almost everywhere in KwaZulu-Natal. Similarly, the study of Mavela and Cibane communities in Ndwedwe reveals a transport crisis, like in the Melmoth area. Tarred access and community roads are identified as a development priority by the community (Sotshongaye \& Moller, 2000). According to these authors, the Mavela women have fairly good access to public transport, but their main problem is that the taxis drop passengers in the main road far from their homes because there are no internal roads. Consequently, the women walk long distances from the drop-off point, often carrying heavy packages of purchases made in town. A study done by Leach reveals that the people in KwaZulu-Natal, including rural Melmoth, are under resourced in many ways. Among others, Leach (1999:163) points out that the road infrastructure in rural areas has been neglected for decades, making the use of travelling libraries impossible to many communities, and distances are considerable, making access to town libraries difficult.

Non-availability of proper roads hinders the smooth running of transport in the area and also interferes with movement and communication. Information is not readily flowing and transferred among the rural women and between the rural women and rural community workers and leaders as well as civil servants.

\section{Job/career information}

A noticeable number $(10 \%)$ of rural women indicated the need for information on career or job opportunities. It is widely known that in rural areas the communities are neglected most of the time, there is a high level of unemployment which leads to poverty. As noted by Hirschowits (2000:25), KwaZulu-Natal is rated among provinces with a poverty level of $26 \%$. Economists consider such poverty levels to be quite high. The reasons for seeking jobs/career related information, among others, were the high unemployment rate, bad working conditions for those who are working in sugar cane fields, on forest farms and orange and banana farms. Thus, they want alternative jobs and look for better conditions of service. They need to be well equipped with necessary information on careers, education and training, employment opportunities, rights and responsibilities. They are looking for weekend and holiday job information. The young women want to help supplement their parents' provision. Others want to support themselves and their families. The Melmoth rural women are no exception. Job/career/employment needs by women have also been noted by Mchombu. The author observes that this need is for self-employment, improved chances of finding work, improved chances of acquiring training and awareness of self-employment opportunities (Mchombu, 1999:240). 


\section{Information sources}

The results reveal that friends, neighbours and relatives (65\%) are preferably used as information sources by the rural women in Melmoth. This concurs with the findings from the rural informants of this area. This is a typical and common way of transferring information in rural communities. They cannot exploit information available in print media. In addition, oral sources of information are always readily available. It is also common knowledge that people tend to exploit what is closer to them than what is far away. This conception is confirmed by close environment mentality, a major influence on information seeking and exchange as witnessed in other related studies (Ocholla 1998, 1999; Ikoja-Odongo 200।, 2002; Mooko 2002, and Ikoja-Odongo \& Ocholla 2003) These information sources are readily available almost all the time when needed. Similarly, oral information transfer, as observed by Leach (1999), is as old as humankind. Leach describes it as immediate and requiring no technology. Although he laments that it lacks permanence, he is of the opinion that it is a basic medium of information transfer, which does not require the acquisition of new skills such as reading (Leach, 1999:165).

It is noted with surprise that nurses/health workers were rated below educators as the information sources preferred by rural informants. This contradicts what was initially said in terms of information needed by rural women, where health information was rated second to information on agriculture. The reason could be that there are fewer clinics around the area than schools. They are able to meet with teachers/educators easily. Their children have contact with educators, which might result in parents, too, having familiarity with them. Nurses visit the rural areas occasionally, using mobile vehicles. They do not stay long with these women; thus rural women and rural informants are not familiar with each other.

A small number of rural women (2\%) opt for newspapers/magazines which can give them the information they need. This is a factor caused by the level of illiteracy and unavailability of print media. It has been noted that friends, neighbours and relatives have been cited as priority sources of information.

10. Reasons for dissatisfaction

A quite substantial number (76\%) of rural women in Melmoth showed dissatisfaction with the information they obtain from the information sources they indicated.

For those who were not satisfied, a number of reasons were provided. For transport and communication information, it was indicated that there are no relevant people with sufficient information on this aspect who can guide them.

Other women indicated that although they got the information, it was either not relevant to their needs or it was not helpful. This could be attributed to poor communication systems available in this area and over-dependence on limited sources of information.

A large number $(78 \%)$ did nothing after being dissatisfied with the information they got. That is, after the defeat, they fold their arms and do nothing further. This is obviously the wrong way of creating development and progress.

It is pleasing, though it does not happen frequently, to note that some (4\%) opted for books, while others ( $18 \%)$ ask their parents for information they did not get from information sources they had chosen.

11. Uses of information

Menou (1998) notes that information is used when solving problems, in the broadest sense of any situation calling for action. He appreciates the importance of information to the outcome of any situation as lubricant to the performance of a car (Menou, 1998:II).

Thus, the rural women in Melmoth, like any other women, use information for various purposes. They consulted, visited and followed the instructions, used relevant people and places where possible. They also took precautions when needed. This is in line with the rural informants' views on whether they think rural women use information. Responses include:

- They use information to gain knowledge and to improve on their daily performances and duties. They also uplift themselves and their families on nutritional, education and health matters.

Various reasons hindering access to information were given. Among others, these were:

- I usually get outdated information from the newspaper, which my aunt brings from the kitchens.

- There are no newspaper/magazine shops around, I get to read the newspaper when I am visiting my mum who is a domestic worker.

- At home we are so busy that I do not have time to sit and relax and listen to radio news or any programme.

It is clear that rural women in Melmoth are missing out on important information for a number of reasons, yet they need it.

12. Obstacles that hinder information access by the rural women

It is noted that the rural women of Melmoth do not communicate frequently in order to transfer or receive information at the time they need it. This could be attributed to a lack of time to relax. As indicated in their daily activities, time is a 
hindering factor to accessing information. Rural informants concurred that rural women in that area do not make time for workshops, seminars or meetings.

Financial obstacles $(22,9 \%)$ were mentioned by the rural women, where facts like inadequate or no money to buy information media such as radios, newspapers, magazines and television sets were mentioned. It is very obvious of course that even if these media were available, sustainability still poses a problem.

The age $(4,6 \%)$ issue, especially in rural areas, is very significant. As the rural women stated, the age problem is indeed the typical stereotyping exercise of a rural community. The younger you are, the greater the chances are for a person not to be listened to by the older people.

It is also regarded as disobedience to address adults while you are young, despite the importance of the information you possess. The Melmoth rural women are facing such problems which hinder their access to information.

Fright $(9,2 \%)$ is still dominating most people, especially Africans in rural areas. The fear of expressing one's feelings about something is still dominating the lives of people in general, but women in particular. That is why women indicated it as a hindrance when they try to access information.

It was surprising to hear that 109 (100\%) of the sampled women in rural Melmoth indicated that there is no cultural or traditional barrier which prevents them from accessing information. However, such factors as age and fright mentioned above are attributed to cultural barriers. Women may not attend meetings called in the area without authorisation from 'senior' family members. The women have to stay at home, look after children and fulfil household chores.

Regarding the media or information sources used to access information, the majority indicated that friends, neighbours and relatives are their sources of information. A low number use radios as their sources of information. Their reason could be that they lack time to listen to radio programmes due to the fact that they are very busy with household activities. It can also be that the rural women communicate very well orally with the people they are familiar with, like friends, relatives or neighbours.

It is likely that those (12\%) who regard teachers as their sources of information are school children or young women of the area. As Fourie (1999) observes, the youth rely on school as a source of information on opportunities in the job market.

Accessibility of an information source is vital to a person who needs information at that point in time. The reason why the rural women (33\%) continue using a particular media is because of its availability all the time, and that is not surprising. It is possible that they can wake their neighbours up any time they need some kind of information. Thus, their neighbours are a source which is always available but not necessarily reliable.

It is noticed that one of the problems when using media or information sources is that rural women and their friends, relatives and neighbours are staying in the same vicinity, and they might possibly be exposed to the same information. This could be true because one cannot think of any other possible way friends can get new information without women knowing or without a different exposure.

\section{Conclusions}

It was revealed that Melmoth rural women have information needs that are identified in the fields of agriculture, health, education, business, jobs/careers, transport/roads, security, welfare and pensions, and entertainment. It is further noted that they largely seek information from friends, relatives and neighbours, who are closer to them. The use of extension workers, who are government agents representing a variety of government departments in the rural areas, is also widespread. However, the use of media such as radios, newspapers or television to seek information is insignificant, as access is hampered by lack of resources to facilitate access. Some of the information available to rural women, such as agricultural, health and educational information, is not meeting their information needs because the packaging is not done with their needs in mind. Illiteracy, lack of time, unavailability of proper places for information access, poor infrastructure such as roads, telephones and electricity are some of the problems which prevent access of information by the rural women.

Evidently, the rural women prefer that information be provided to them all the time and any time they need it. Oral transfer of information is highly preferred and the use of rural informants recommended. The professionals working in the rural areas such as teachers, nurses and social workers are preferred to deliver information to the community. Recognising that libraries are ill-equipped, and poorly located to provide information to the community, schools, clinics, hospitals and grocery stores should be exploited for audio-visual information services. Many women usually converge in such places to buy groceries or collect their medication or collect their children from schools. It is noted in South Africa that such public places where people wait for services are increasingly targeted by advertisers for the promotion of 
consumer products and services through cable television channels. The facility can be explored for effective information delivery and services.

Several assumptions suggested at the beginning of this study were verified. For example, it was confirmed that the rural women of Melmoth use the information sources readily available to them such as friends, relatives and neighbours, who possess largely the same information content as they do. They therefore do not always get information they need, which leads to dissatisfaction with the information provided. It is therefore true that unavailability of relevant information in approppriate format hinders their exploiting of information. It was, however, disproved that conservative traditions deter Melmoth women from accessing information from the respondents' point of view. For example, it was noted that rural women of Melmoth are always busy with household chores, and they do not have enough time to access information by participating at traditional meetings (Imbizo) or workshops. Most of them do not use modern media such as radios when their husbands or mothers-in-law do not approve of these, or they are totally not there. These, however, are culturally based factors which hinder information exploitation. Ultimately, although all 109 (100\%) rural Melmoth women sampled for this study indicated that there were no cultural barriers blocking them from information access and use, the initial viewpoint that cultural barriers inhibit information access could be maintained as responses given contradicted the reality on the ground. It is observed that the rapid rural development initiative in South Africa is already bringing information closer to the rural population. However, problems raised in the study in relation to inaccessibility of information due to illiteracy, poverty, unemployment, relevancy and lack of infrastructure are shared with most countries in the 'majority world'. Solutions to these problems vary from country to country and South Africa has the potential to solve most of the problems sooner than most affected countries.

\section{References}

Bailey, K. 1994. Methods of social research. New York: Free Press.

Basow, SA. 1992. Gender stereotypes and roles. California: Pacific Grooves: Brookes/Cole.

Cillie, R. M. 2000. The role of Department of Arts, Culture, Science and Technology in facilitating access to information. Mousaion. Vol. I8(1):109-129.

Fisher, Shelagh \& Oulton, Tony. 1999. The critical incident technique in Library and Information management research. Education for Information. Vol. I7(2): I I3-I36.

Fourie, J. 1999. Educational and vocational information needs of high school learners, implication for youth information services in South Africa. Mousaion Vol. I7(2):66-8I.

Friedman, M. 1989. Gender and development: Literature review. Pietermaritzburg: Institute of Natural Resources - INR occasional paper No. 23.

Henderson, J. 2003. South Africa Survey 2002/2003. South African Institute of Race Relations: Johannesburg.

Hirschouwitz, R. 2000. Measuring poverty in South Africa. Pretoria: Statistics South Africa

Ikoja-Odongo, R. 200I. A study of information needs and uses of the Informal Sector In Uganda: preliminary findings. Libres. Vol.I I (I) available online: http://libres.curtin.edu.au/libres. Accessed on: 30th April 2003.

Ikoja-Odongo, JR. 2002.Insights into the information needs of women in the informal sector of Uganda. South African Journal of Libraries and Information Science, Vol.68,Nol:39-52.

Ikoja-Odongo R. and Ocholla, DN 2003. Information Behavior of Fisherfolks in Uganda. International Library and Information Research, Vol. 25 No.1:89-105

Leach, A. 200I. The best thing is communicating verbally. NGO information provision in rural KwaZulu-Natal and some observations relating to library and information services. In. Stilwell, C.; Leach, A. \& Burton, S. (eds.) Knowledge, information and Development: an African perspective. University of Natal: Pietermaritzburg:163-186.

Mchombu, C. M. 2000. Information needs of business women in Botswana. International Information and Library review:39-67. Available on line: http.www.idealibrary.com

Mchombu, Kingo. 200I. Measuring the impact of information on rural development. In Stilwell, C; Leach, A. \& Burton, S. (eds). Knowledge, information and development: an African perspective. Pietermaritzburg: University of Natal: 229-238

Menou, M.J. 1998. Does information make any difference? Research Bulletin, 1998(21):10-12

Mooko,NP 2002. The use and awareness of women's groups as sources of information in three small villages in Botswana. South African Journal of Libraries and Information Science, Vol. 68(2): I04-II I

Ngimwa, P., Ocholla, D.N., Ojiambo, JB 1997. Media Accessibility and Utilization by Kenyan Rural Women. International Information and Library Review, Vol. 29:45-66

Ocholla, D.N. 1999. Insight into information seeking and communicating behavior of academics. International Information and Library Review. Vol. 31:119-143

Ocholla, DN. 1998. Information Consultancy and Brokerage in Botswana. Journal of Information Science, 24(20): 17-29.

Purnell, M. \& Coetser, L. 200I. Information erosion and agricultural libraries in South Africa. Meta-info Bulletin. Vol. I0(3):25-36.

Rutakumwa,W. \& Krogman, N.T. 2000. Rural Ugandan women's views about their health and health services. WE International (48/49) http.www. Ebscohost.

Saito, K. et al. 1994. Raising the productivity of women farmers in Sub-Saharan Africa. Washington: World Bank

Sotshongaye, A. \& Moller, V. 2000. We want to live a better life like other people: Self-assessed development needs of rural women in Ndwedwe, KwaZulu-Natal. Development Southern Africa Vol. I7 (I). Available: http.www. Ebscohost. [retrieved II/ $6 / 01]$ 